
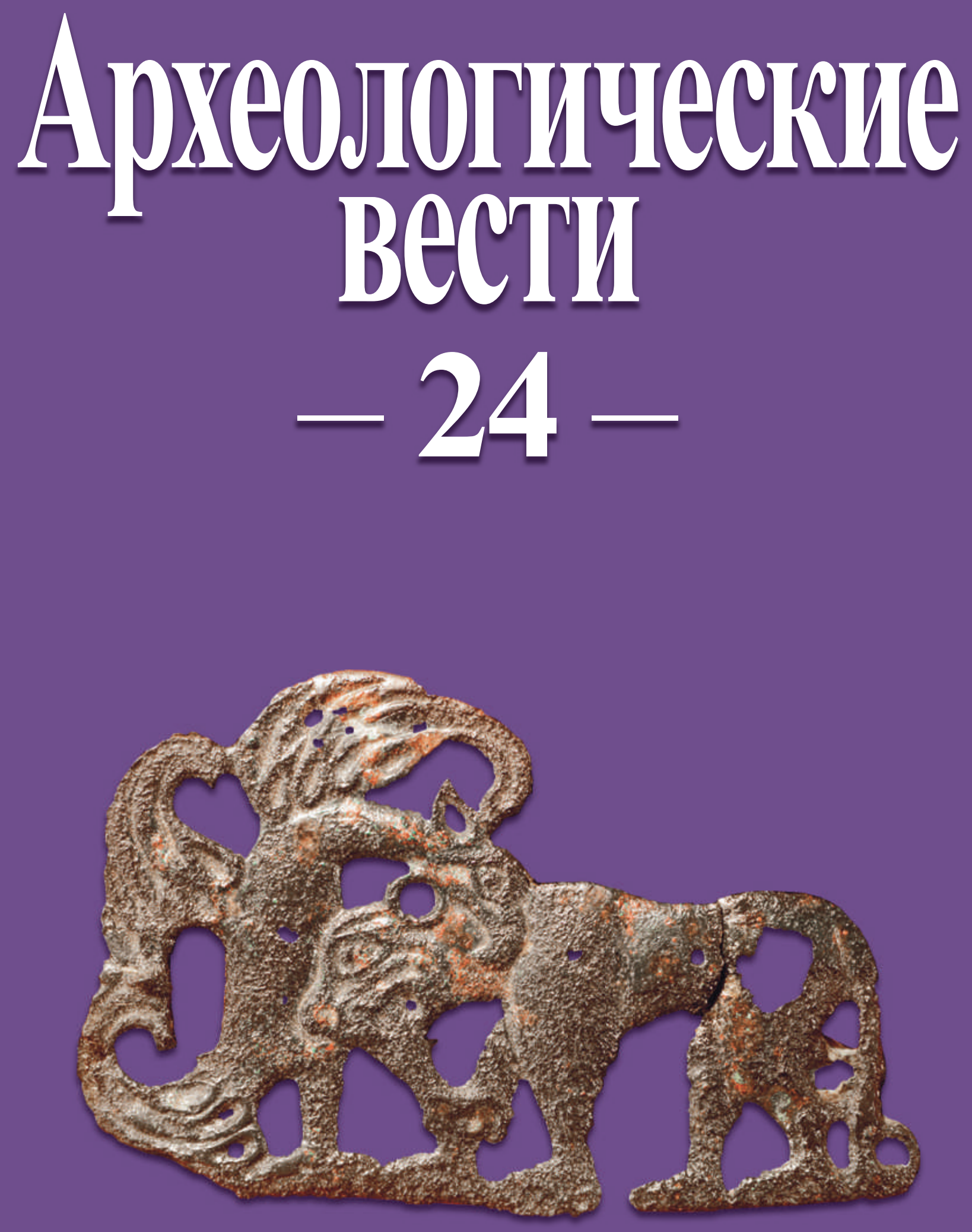


\author{
РОССИЙСКАЯ АКАДЕМИЯ НАУК \\ ИНСТИТУТ ИСТОРИИ МАТЕРИАЛЬНОЙ КУЛЬТУРЫ \\ RUSSIAN ACADEMY OF SCIENCES \\ INSTITUTE FOR THE HISTORY OF MATERIAL CULTURE
}

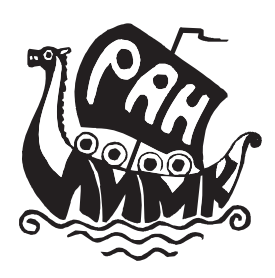




\title{
Archaeological news
}

\author{
24 \\ (2018)
}

SAINT-PETERSBURG 2018 
Археологические вести

\author{
24 \\ (2018)
}

САНКТ-ПЕТЕРБУРГ

2018 
Издание основано в 1992 году

Редакционная коллегия:

член-корреспондент РАН Е. Н. Носов (главный редактор), академик РАН В. Л. Янин, академик РАН Н. А. Макаров,

Н. В. Хвощинская (зам. главного редактора), О. И. Богуславский, М. Ю. Вахтина, Т. С. Дорофеева (отв. секретарь),

М. Т. Кашуба, В. А. Лапшин, Н. Ю. Смирнов, Л. Г. Шаяхметова

Рецензенты:

кандидат исторических наук В. А. Алёкшин

доктор исторических наук С. И. Кочкуркина

Археологические вести, Ин-т истории материальной культуры РАН. - 1992. -

Вып. 24 / [Гл. ред. Е. Н. Носов]. - СПб., 2018. - 428 с., ил.

ISSN 1817-6976

В очередной сборник ежегодника ИИМК РАН включены статьи, посвященные новейшим исследованиям в области археологии, истории и культуры. Впервые вводятся в научный оборот материалы, полученные в результате изучения поселений и погребальных памятников от эпохи камня до средневековья на территории Евразии. В ряде статей рассматриваются конкретные археологические комплексы и отдельные категории материала. В специальный раздел сборника включены работы по актуальным проблемам археологии, касающиеся древностей эпохи бронзы и раннего железа Северного Причерноморья и лесостепной зоны Восточной Европы. В сборнике представлены рецензии на новейшую историко-археологическую литературу и информация о прошедшем в октябре 2017 г. V (XXI) Всероссийском археологическом съезде Отдельный раздел посвящен истории науки. Среди авторов ежегодника ученые из России, Азербайджана, Казахстана, Молдовы, Франции и Германии.

This yearbook of IIMK RAS includes a collection of articles concerned with the most recent researches in the sphere of archaeology, history and culture. It is the first time that some materials obtained through investigation of settlements and burial sites dating from the Stone Age to the Middle Ages in the territory of Eurasia are scientifically published. In a number of the papers, particular archaeological complexes and categories of finds are discussed. A special section of the collection considers works on the urgent problems of archaeology and antiquities of the Bronze Age and Early Iron Age of the Northern Black Sea Region and forest-steppe zone of Eastern Europe. The present collection presents reviews of the latest historical and archaeological publications and information on the 5th (XXIth) All-Russian Archaeological Congress held in October, 2017. A separate section is dedicated to the history of science. Among the authors of this yearbook there are scientists from Russia, Azerbaijan, Kazakhstan, Moldova France and Germany.

Обложка:

Первая страница - Бронзовая пряжка-пластина из кургана № 43 могильника Ала-Тей 1 (к статье М. Е. Килуновской и П. Леуса) First page - Bronze plate/buckle from kurgan no. 43 at the cemetery of Ala-Tey 1 (article by M. E. Kilunovskaya and P. M. Leus)

Четвертая страница - Двор Ладожской крепости. Карта вертикального градиента поля аномалий силы тяжести: а - изолинии вертикального градиента поля аномалий силы тяжести; б - линии геофизических профилей; в - буровые скважины (1989 г.); г- фрагменты разрушенных крепостных стен; д-предполагаемые контуры погребенных развалин каменной кладки, обнаруженные при раскопках А. Н. Кирпичникова (к статье Н. В. Григорьевой, В. В. Кошевого, О. Ю. Медведева)

Fourth page - Courtyard of the Ladoga fortress. Map of the vertical gradient of the field of anomalies of the gravitation force; a - isolines of the vertical gradient of anomalies of the gravitation force; 6 - lines of the geophysical profiles; B - boreholes (1989); $\Gamma-$ fragments of the ruined defensive walls; д - presumed outlines of the buried ruins of the stonework found during A. N. Kirpichnikov's excavations (article by N. V. Grigor'yeva, V. V. Koshevoy \& O. Yu. Medvedev) 


\section{СОДЕРЖАНИЕ}

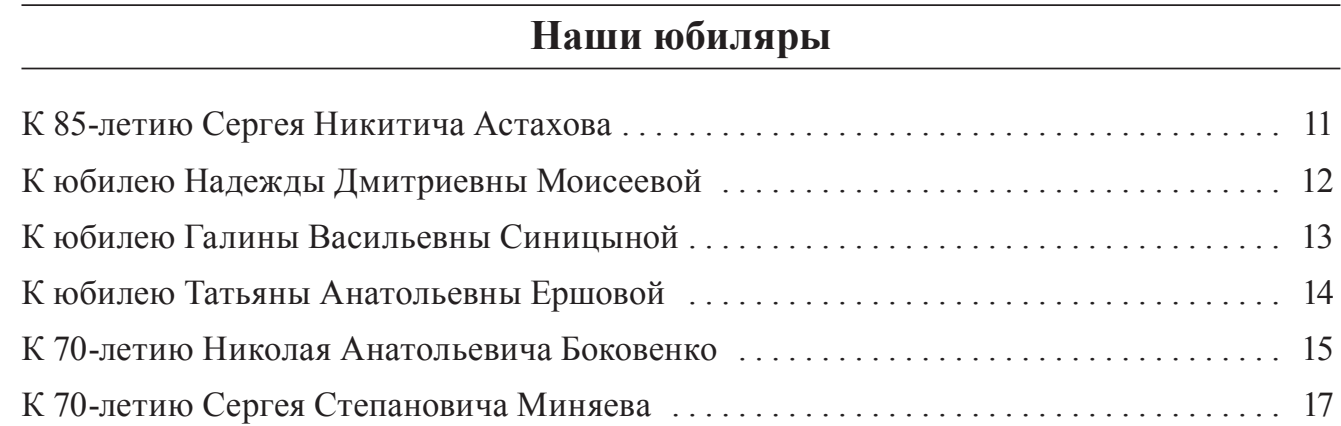

\section{Новые открытия и исследования}

C. А. Кулаков. Раннепалеолитическая стоянка Богатыри/Синяя Балка

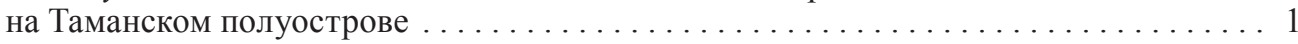

Н. К. Анисюткин, С. А. Кулаков, А. Л. Чепальга. Исследования местонахождений раннего палеолита на высоких морских террасах Южного Крыма в 2016 г. . . . . . . . 33

А. М. Скоробогатов, И. В. Федюнин. Новые материалы палеолита и энеолита на южной границе лесостепного Подонья. . . . . . . . . . . . . . . . . . . . . . 42

C. Н. Разумов. Собака в культовой практике населения Северо-Западного

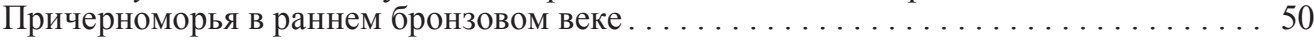

В. А. Трифонов, Н. И. Шиилина, А. Ю. Лобода, Н. Н. Колобылина,

E. Ю. Терещенко, Е. Б. Яцииина. Золотые тонкостенные бесшовные бусы из дольмена раннего бронзового века в кургане № 2 у станицы Царская, СевероЗападный Кавказ: технология изготовления и культурно-исторический контекст . . 68

И. П. Лазаретов, А. В. Поляков. Святилище раннего бронзового века в Туве . . . . 83

В. В. Алейников, В. П. Глебов, В. Я. Стеганцева. Погребение с повозкой эпохи средней бронзы в бассейне реки Деркул в Тарасовском районе

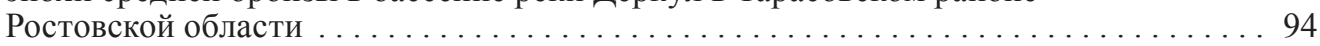

И. А. Кукушкин, Е. А. Дмитриев, А. И. Кукушкин. Каражартас - новый социальностратифицированный некрополь бегазы-дандыбаевской культуры (предварительные результаты исследований) $\ldots \ldots \ldots \ldots \ldots \ldots \ldots \ldots \ldots \ldots$

С. А. Фидельский, М. В. Иващенко, В. С. Синика. Амфорные клейма средиземноморских центров из поселения Чобручи на левобережье Нижнего Днестра . . . . . . . . . . . . . . . . . . . . . . . 110

M. Е. Килуновская, П. М. Леус. Новые материалы улуг-хемской культуры в Туве . . 125

M. М. Казанский. Зооморфные и антропоморфные пряжки и контакты Восточной Прибалтики с Византией в эпоху переселения народов . . . . . . . . . 153

T. А. Кулиев. Из истории монетного двора Дербента . . . . . . . . . . . . . . . . . . 169 
Н. В. Хвощинская. К интерпретации кладов серебряных гривен в Восточной Европе

Н. В. Григорьева, В. В. Кошевой, О. Ю. Медведев. Археолого-геофизические исследования на территории Ладожской крепости (опыт применения метода высокоточной гравиметрии для получения данных о рельефе местности)

M. О. Жуковский. Инструменты для взвешивания с граффити

из раскопок Новгорода . . . . . . . . . . . . . . . . . . . . . . . . . . . . . . . . . . . . . 198

B. В. Яблончук. Топография актовых печатей Новгорода XI-XV вв.

(по материалам Неревского и Троицкого раскопов) . . . . . . . . . . . . . . . 207

П. А. Миляев. Находки деталей ручного огнестрельного вооружения второй половины XV - XVI в. из Старой Ладоги и крепости Орешек в свете восточно- и западноевропейских аналогий $\ldots \ldots \ldots \ldots \ldots \ldots \ldots \ldots$

Л. М. Дмитренко. Результаты исследования керамики поселения Ла-Пайя (провинция Сальта, Северо-Западная Аргентина) из собрания МАЭ РАН . . . . . . 239

\section{Актуальные проблемы археологии}

P. A. Мимоход. Происхождение и семантика фигурных пряжек эпохи бронзы в Европе и на Кавказе в контексте ближневосточных влияний . . . . . . . . . . . 249

М. А. Кулькова, М. Т. Кашуба, А. М. Кульков, Н. С. Власенко, Н. А. Гаврилюк, Э. Кайзер. Первые исследования белой пасты для инкрустации керамики раннего железного века в Северном Причерноморье . . . . . . . . . . . . . . 276

B. И. Козенкова. Заметки о некоторых аспектах и векторе развития кобано-скифских взаимоотношений 290

\section{Обзоры и рецензии}

Попытка с негодными средствами, или Непреодоленное непостижимое

Winkler-Horaček L. Monster in der frühgriechischen Kunst. Die Überwindung des Unfassbaren (Image \& Context. Vol. 4. / Ed. F. Lissarrague, R. Schneider \& R. R. R. Smith) Berlin; Boston: De Gruyter, 2015. -

ISBN: 978-3-11-018900-1. - 690 S. 241 Abb. (Рец. И. Ю. Шауба)

Новые подходы к изучению культурного процесса в Восточной Европе

Élite ou Égalité: Северная Русь и культурные трансформации

в Европе VII-XII вв. / отв. ред. Н. И. Платонова. СПб.: Изд. дом «Бранко»,

2017. - ISBN 978-5-903521-50-0 - 310 с. (Рец. А. И. Саксы ) . . . . . . . . . . . . 321

Этноконфессиональный иллюстрированный атлас Ленинградской области

Этноконфессиональный иллюстрированный атлас Ленинградской области /

О. М. Фишман, М. Л. Засецкая, Г. А. Исаченко, Л. В. Королькова,

О. А. Красникова, А. И. Терюков и др. СПб.: ИД «Инкери», 2017.

ISBN 978-5-903562-79-4 - 656 с. (Рец. В. А. Лапшина)

\section{Сотрудничество Восток - Запад}

С. А. Васильев. V (XXI) Всероссийский археологический съезд (Барнаул-Белокуриха, 1-8 октября 2017)

Э. Кайзер, М. Т. Кашуба, О. Н. Щеглова. Первая Международная конференция «Время и материальность: Периодизация и региональная хронология перехода от бронзового к железному веку в Евразии (1200-600 ВСЕ)»

(Берлин, 19-21 марта 2018 г.) 


\section{История науки}

Е. Г. Застрожнова. К истории изучения античного наследия Крымского полуострова в начале $1920-$ х гг. . . . . . . . . . . . . . . . . . . . . . 339

A. В. Курбатов. История изучения кожевенного дела средневековой Руси .. . . . 349 А. А. Пескова, И. В. Антипов, Д. Д. Ёлиин, К. А. Михайлов, А. Е. Мусин. Археология красоты: опыт творческой биографии Марианны Малевской . . . . 358 Список научных трудов Марианны Владимировны Малевской-Малевич

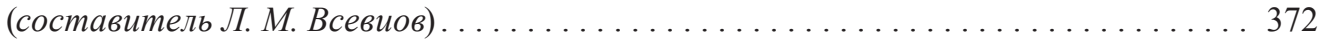

\section{Персоналии}

M. Е. Мазуренко. Лев Михайлович Всевиов . . . . . . . . . . . . . . . . . . . . . .377

Л. М. Всевиов. Издательская деятельность Императорской Археологической комиссии ................................... 383

Ю. А. Виноградов. Последнее письмо академика С. А. Жебелёва . . . . . . . . . . . . .401

Ю. А. Виноградов, И. Ю. Шауб. Разбирая архив В. И. Денисовой . . . . . . . . . . . .405

Ю. А. Виноградов. Два письма из личного архива В. И. Денисовой . . . . . . . . . . .411

\section{Хроника}

C. А. Васильев. Памяти Василия Прокофьевича Любина (1918-2018) 


\section{Content}

\section{Our jubilees}

To the $85^{\text {th }}$ anniversary of Sergey Nikitich Astakhov $\ldots \ldots \ldots \ldots \ldots \ldots \ldots \ldots \ldots$

To the jubilee of Nadezhda Dmitrievna Moiseeva. . . . . . . . . . . . . . . 12

To the jubilee of Galina Vasil'yevna Sinitsyna . . . . . . . . . . . . . . . . . . . 13

To the jubilee of Tat'yana Anatol'yevna Ershova. . . . . . . . . . . . . . . . . 14

To the $70^{\text {th }}$ anniversary of Nikolay Anatol'yevich Bokovenko $\ldots \ldots \ldots \ldots \ldots \ldots$

To the $70^{\text {th }}$ anniversary of Sergey Stepanovich Minyaev $\ldots \ldots \ldots \ldots \ldots \ldots \ldots$

\section{New discoveries and studies}

S. A. Kulakov. Early Palaeolithic site of Bogatyri/Sinyaya Balka on the Taman Peninsula . . . . . . . . . . . . . . . . . . . . . . . . . . . . . . . . . . . . . 19

N. K. Anisyutkin, S. A. Kulakov, A. L. Tchepalyga. Studies of Early Palaeolithic sites on the high marine terraces of Southern Crimea in $2016 \ldots \ldots \ldots \ldots \ldots \ldots \ldots$

A. M. Skorobogatov, I. V. Fedyunin. New Palaeolithic and Eneolithic materials from the southern border of the Forest-Steppe Don region . . . . . . . . . . . . . 42

S. N. Razumov. Dog in Ritual Practice of the North-Western Black Sea

Population of the Early Bronze Age. .......................... 50

V. A. Trifonov, N. I. Shishlina, A. Yu. Loboda, N. N. Kolobylina,

E. Yu. Tereshchenko, E. B. Yatsishina. Gold thin-walled seamless beads from a dolmen of the Early Bronze Age in kurgan no. 2 near the Cossack village of Tsarskaya, Northwestern Caucasus: the technology of manufacturing

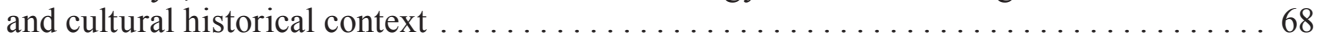

I. P. Lazaretov, A. V. Polyakov. Sanctuary of the Early Bronze Age in Tuva . . . . . . . . 83

V. V. Aleynikov, V. P. Glebov, V. Ya. Stegantseva. Burial of the Middle Bronze Age with a cart in the basin of the Derkul River in Tarasovsky District of Rostov Oblast . . . 94

I. A. Kukushkin, E. A. Dmitriev, A. I. Kukushkin. Karazhartas or a new socially stratified necropolis of the Begazy-Dandybay culture (preliminary results of researches) . . . . . 102

S. A. Fidelskiy, M. V. Ivashchenko, V. S. Sinika. Amphora stamps of Mediterranean centres from the site of Chobruchi on the left bank of the Lower Dniester . . . . . . . 110

M. E. Kilunovskaya, P. M. Leus. New evidence on the Ulug-Khem culture in Tuva . . . 125

M. M. Kazanskiy. Zoomorphic and anthropomorphic buckles and contacts of Eastern Baltic region with the Byzantine Empire in the Great Migration period . . . 153

T. A. Kuliev. From the history of the Derbent mint ...................... 169 
N. V. Khvoshchinskaya. Interpretation of hoards of silver neck rings

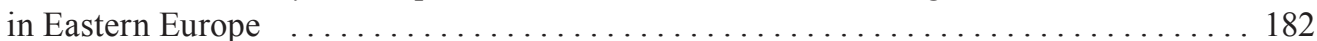

N. V. Grigor'yeva, V. V. Koshevoy, O. Yu. Medvedev. Geophysical archaeological investigations in the territory of the Ladoga fortress (experiment on application of the method of high precision gravimetry

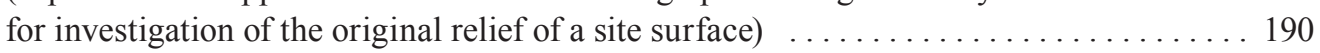

M. O. Zhukovskiy. Weighing instruments with graffiti from excavations in Novgorod ... 198

V. V. Yablonchuk. Topography of official seals in Novgorod of the $11^{\text {th }}-15^{\text {th }}$ century (finds from the Nerevsky and Troitsky excavations) $\ldots \ldots \ldots \ldots \ldots \ldots \ldots \ldots \ldots . \ldots \ldots$

P. A. Milyaev. Finds of parts of hand firearms of the second half of the $15^{\text {th }}-16^{\text {th }}$ century from Staraya Ladoga and the fortress of Oreshek in the view of East- and West-European parallels

L. M. Dmitrenko. Results of the investigation of pottery from the settlement of La Paya (Salta Province, Northwestern Argentina) from the collection of the Museum of Anthropology and Ethnography RAS 239

\section{Topical Problems of Archaeology}

R. A. Mimokhod. The origin and semantics of figured buckles from Bronze Age Europe and Caucasus in the context of Near Eastern influences ................ 249

M. A. Kul'kova, M. T. Kashuba, A. M. Kul'kov, N. S. Vlasenko, N. A. Gavrilyuk,

E. Kaiser. First investigations of white paste for inlaid ceramics of the Early Iron Age from the northern Black Sea littoral . . 276

V. I. Kozenkova. Essay on some aspects and the vector of development of Koban-Scythian interrelations

\section{Review Articles and Book Reviews}

An attempt with unfit means or the Unsurmounted inconceivable

Winkler-Horaček L. Monster in der frühgriechischen Kunst. Die Überwindung des Unfassbaren (Image \& Context. Vol. 4. / Ed. F. Lissarrague, R. Schneider \& R. R. R. Smith) Berlin; Boston: De Gruyter, 2015. -

ISBN: 978-3-11-018900-1. - 690 S. 241 Abb. (Rev. by I. Yu. Schaub)

New approaches to studies of the cultural process in Eastern Europe

Élite ou Égalité: Северная Русь и культурные трансформации в Европе VII-XII вв. / отв. ред. Н. И. Платонова. СПб.: Изд. дом «Бранко», 2017. - ISBN 978-5-903521-50-0 - 310 c. (Rev. by A. I. Saksa)

Illustrated ethno-confessional atlas of Leningrad Oblast

Этноконфессиональный иллюстрированный атлас Ленинградской области /

О. М. Фишман, М. Л. Засецкая, Г. А. Исаченко, Л. В. Королькова, О. А. Красникова,

А. И. Терюков и др. СПб.: ИД «Инкери», 2017. ISBN 978-5-903562-79-4 - 656 с.

(Rev. by V. A. Lapshin) . ......................................... 325

\section{The East-West Cooperation}

S. A. Vasil'yev. The $\mathrm{V}^{\text {th }}$ (XXI) All-Russian archaeological congress

(Barnaul-Belokurikha, October 1-8, 2017) 
E. Kaiser, M. T. Kashuba, O. A. Shcheglova. $1^{\text {st }}$ International conference «Time and materiality: Periodization and regional chronologies at the transition from Bronze to Iron Age in Eurasia (1200-600 BCE)» (Berlin, 19-21 March 2018)

\section{History of Science}

E. G. Zastrozhnova. History of the study of the ancient heritage in the Crimean Peninsula in the early 1920s

A. V. Kurbatov. History of studies of leather tanning in mediaeval Rus

A. A. Peskova, I. V. Antipov, D. D. Yolshin, K. A. Mikhaylov, A. E. Musin.

The archaeology of beauty: essay on the creative biography of Marianna Malevskaya . . 358

List of scientific works of Marianna Vladimirovna Malevskaya-Malevich

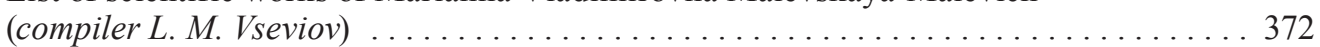

\section{Personalia}

M. E. Mazurenko. Lev Mikhaylovich Vseviov. . . . . . . . . . . . . . . 377

L. M. Vseviov. The publishing activities of the Imperial Archaeological Commission. . . 383

Yu. A. Vinogradov. The last letter of the Academician S. A. Zhebelyov . . . . . . . . 401

Yu. A. Vinogradov, I. Yu. Schaub. Examining the archives of V. I. Denisova ... . . . . 405

Yu. A. Vinogradov. Two letters from V. I. Denisova's personal archives . . . . . . . . . .411

\section{Chronicle}

S. A. Vasil'yev. In memory of Vasily Prokofievich Lubin (1918-2018) . . . . . . . . . . 421

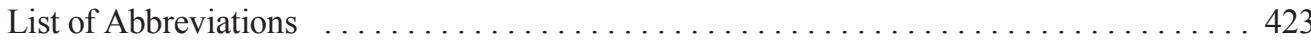




\title{
ИССЛЕДОВАНИЯ МЕСТОНАХОЖДЕНИЙ РАННЕГО ПАЛЕОЛИТА НА ВЫСОКИХ МОРСКИХ ТЕРРАСАХ ЮЖНОГО КРЫМА в 2016 Г. ${ }^{1}$
}

\author{
Н. К. Анисюткин, С. А. Кулаков, А. Л. Чепалыга²
}

Аннотация. В статье приведены предварительные результаты обследования в 2016 г. геоархеологических местонахождений раннего палеолита, обнаруженных в 2014-2015 г2. палеогеографом А. Л. Чепальгой на высоких 100-метровых морских террасах южного берега Крыма. Удалось установить присутствие на местонахождениях Коз и Эчки бесспорных находок раннего и среднего палеолита. Из них наибольший интерес представляют архаичные артефакты из местонахождения Коз, где в галечниках высокой террасы найдены выразительные галечные орудия, сопоставимые с древнейшим ранним палеолитом типа Mode 1.

Annotation. This paper presents preliminary results of the surveys of 2016 at the geoarchaeological sites of the Early Palaeolithic period discovered in 2014-2015 by the palaeogeographer A. L. Tchepalyga on 100-metre high marine terraces on the Southern coast of Crimea. It proved possible to discover undisputable finds of the Early and Middle Palaeolithic at the sites of Koz and Echki. Of these, archaic artefacts from the site of Koz are of the greatest interest. There, expressive pebble tools comparable to the Earliest Palaeolithic artefacts of Mode 1 type were found among the pebbles on a high terrace.

Ключевые слова: Крым, высокие морские террасы, ранний и средний палеолит.

Key words: Crimea, high sea terraces, Early and Middle Palaeolithic.

DOI: 10.31600/1817-6976-2018-24-33-41

В предлагаемой статье речь идет о находках каменных изделий из плейстоценовых отложений высоких морских террас, впервые обнаруженных А. Л. Чепалыгой на южном берегу Крымского полуострова еще в 2014-2015 гг. (рис. 1). По мнению Н. К. Анисюткина, знакомившегося в Москве с коллекциями этих двух лет, ряд предметов действительно являются каменными изделиями ископаемых людей. Все они имеют вполне архаичный облик и сопоставимы с артефактами раннего и среднего палеолита (Чепальга и др., 2015. С. 5-22).

1 Работа выполнена при финансовой поддержке РФФИ (проект № 16-06-60514) и в рамках направления ПФНИ: 190. Изучение эволюции человека, обществ и цивилизации, человек в истории и история повседневности, традиции и инновации в общественном развитии. Анализ взаимоотношений власти и общества (тема № 0184-2018-0012. «Древнейшие обитатели России и сопредельных стран: пути и время расселения, эволюция культуры и общества, адаптация к природной среде».

2 Анисюткин Н. К., Кулаков С. И. - Россия, 191186, СанктПетербург, Дворцовяя наб., 18. Институт истории материальной культуры РАН, Отдел палеолита. E-mail: leonid. dictyoptera@gmail.com; e-mail: kazvolg@yandex.ru.

Чепалыга А. Л. - Россия, 119017, Москва, Старомонетный пер., 29. Институт географии РАН. E-mail: tchepalyga @mail.ru.
Важно упомянуть, что А. Л. Чепалыга, предварительно публикуя эти материалы, назвал их «олдованскими», основываясь на предполагаемом им эоплейстоценовом возрасте высоких террас. Однако в настоящее время этот вывод требует надежных доказательств.

Для подтверждения реальности открытых местонахождений А. Л. Чепалыга организовал на свой грант дополнительные археологические исследования. Археологические изыскания 2016 г. возглавил известный специалист-кавказовед С. А. Кулаков (ИИМК РАН), на имя которого и был получен Открытый лист. Так был создан Крымский отряд ИИМК РАН.

Были обследованы высокие террасы в районе села Курортное Феодосийского городского округа, террасы и карьер в селе Солнечная Долина Судакского городского округа, а также высокие террасы на восточной окраине г. Судака на предмет поиска находок раннего палеолита. Рассмотрим материалы двух местонахождений с относительно многочисленными артефактами. Не описывается местонахождение Алчак, где найдено всего одно галечное орудие. 


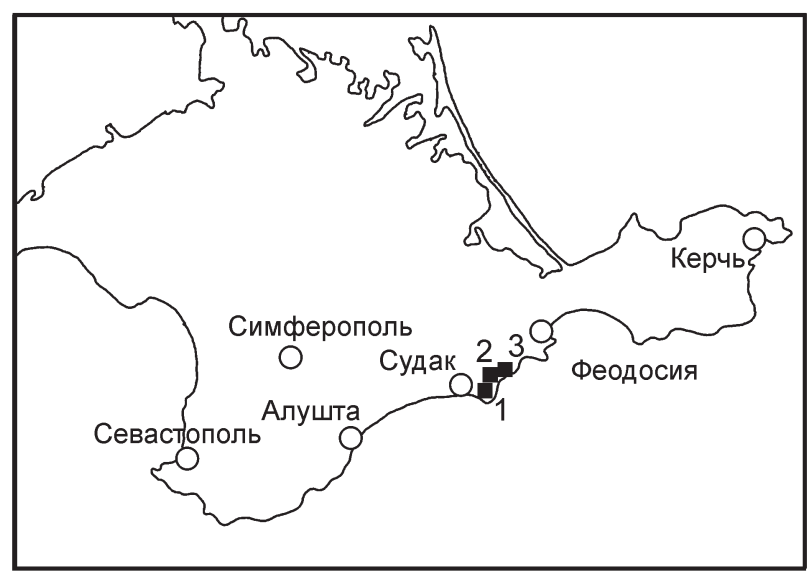

Рис. 1. Археологические обследования в восточной части Крыма: 1 - Алчак; 2 - Коз; 3 - Эчки 1

Fig. 1. Archaeological investigations in eastern Crimea: 1 -Alchak; 2 - Koz; 3 -Echki 1

Местонахождение «Эчки 1». Местонахождение Эчки 1 находится в 1,5 км на запад от пос. Курортное и Карадагского природного заповедника РАН. В 2014-2015 гг. каменные предметы, предположительно артефакты, были собраны А. Л. Чепалыгой на высоком, 100-метровом террасовидном уровне береговых обрывов на правом западном борту Лисьей бухты (Чепальга, 2015. С. 28-42; Чепалыға u дp., 2015. С. 5-22).

Местонахождение представляет собой равнину без видимых резких перегибов и иных крупных форм рельефа площадью около 1 га, имеющую уклон с севера на юг: от подножия хребта Эчки-Даг к морю. С востока и запада она ограничена глубокими оврагами с крутыми и обрывистыми бортами: Лисья Бухта - с востока и Сухой овраг - с запада. Ее поверхность покрыта травянистой растительностью полупустынного типа (местные жители называют это место «Сковорода»), только ближе к горам появляются деревья - отдельно стоящие и небольшие заросли дуба черешчатого.

Координаты местонахождения у подножия хребта Эчки-Даг согласно данным А. Л. Чепалыги - «N44'53'39.03”'E3509'17.33”» (Чепалыга и др., 2015. C. 18).

В результате осмотра объекта и сборов была получена коллекция артефактов - 62 экз. Все каменные изделия были собраны только на современной дневной поверхности отложений почти на всей площади этой равнины. В стенах береговых обрывов, бортах оврагов и в осыпях под ними артефакты не обнаружены. Почти все предметы изготовлены из изверженных пород, источником которых, по мнению А. Л. Чепалыги, является соседний древний вулкан Кара-Даг.

Коллекция каменных изделий, собранная на поверхности склона террасы, представлена несколькими десятками выразительных предметов. К бесспорным артефактам можно отнести почти все, в их числе 47 предметов изготовлены из андезита и четыре - из кремнистого песчаника. ${ }^{3}$ В отличие от андезитовых изделий, песчаниковые имеют слабую заполированность поверхностей. Среди изделий из кремнистого песчаника два можно считать вполне выразительными. Один предмет, возможно, следует отнести к ножевидным орудиям. Он изготовлен на уплощенной плитке овальной формы с несколькими сколами на поверхности и выраженным микрозубчатым лезвием по одному краю. Скорее всего, эта ретушь является следами утилизации. Поперечное сечение двояковыпуклое (рис. 2, 1). Второе орудие также достаточно выразительно. Его поперечный рабочий край обработан полукрутой ретушью, образуя лезвие типа скребка. Остальные изделия из песчаника менее показательны, хотя и имеют заметные следы обработки.

Из андезитовых орудий достаточно показательны два скребла на массивных долечных отщепах. Выпуклый рабочий край первого скребла оформлен полукрутой краевой ретушью. Ему противолежит естественный обушок (рис. 2, 4). Второе скребло также имеет выпуклый рабочий край. Лезвие с брюшка обработано распространенной, многорядной чешуйчатой ретушью, а противолежащий лезвию край оббит серией двусторонних снятий, утончающих корпус орудия. Данное орудие можно определить как скребло с утонченным ретушью корпусом (по Ф. Борду Racloir a dos aminci). С. А. Кулаков предварительно описал это орудие как незаконченное частично двустороннее (рис. 2, 3). Интересной формой можно считать расколотую пополам плоскую андезитовую гальку с уплощенным сколом, формирующим заостренный конец. Это изделие

\footnotetext{
${ }^{3}$ К выделению данных песчаниковых артефактов С. А. Кулаков относится скептически.
} 


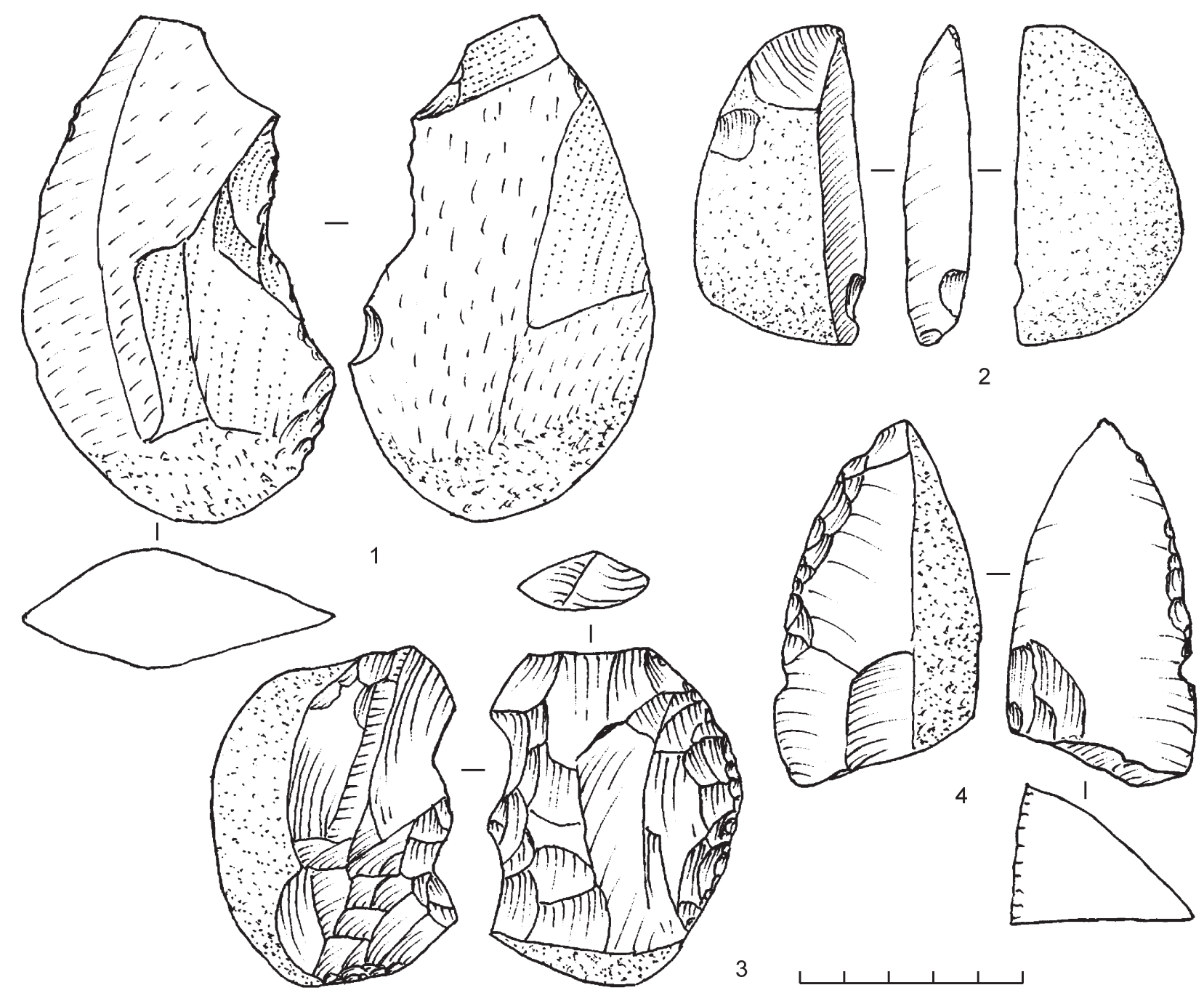

Рис. 2. Местонахождение Эчки 1 , каменные орудия: 1 - ножевидное орудие на плитке песчаника; 2 - обломок андезитовой гальки с плоским сколом острого края; 3, 4 - скребла

Рисунки Н. К. Анисюткина

Fig. 2. Site of Echki 1, lithics: 1 - knife-like tool on a plate of sandstone; 2 - fragment of an andesite pebble with a flat scar at the sharp edge; 3, 4 - scrapers

Drawings by N. K. Anisyutkin

следует отнести к простым галечным орудиям (рис. 2, 2).

В коллекции имеется 15 выразительных отщепов и семь обломков отщепов, в их числе достаточно крупный обломок дистальной части пластинчатого отщепа с микроретушью. Этот пластинчатый отщеп условно можно рассматривать как атипичный леваллуазский. На четырех отщепах имеется мелкая ретушь. На одном крупном отщепе выделяется иррегулярная ретушь, которую, вероятно, можно рассматривать как следы более поздних повреждений. Среди отщепов нет предметов с фасетированными площадками. Остальной материал представлен разнообразными обломками и осколками.

В целом, каменные изделия этого комплекса имеют достаточно развитой облик. Их можно сопоставить либо с начальным средним палеолитом, либо с концом раннего палеолита. Показательна долечная техника раскалывания камня, которая в данном случае не связана с особенностями сырья. К примеру, изготовленные из андезита каменные изделия мустье Юго-Осетии не имеют никаких элементов долечной техники. Здесь господствуют тонкие пластинчатые 
сколы, часто типа леваллуа (Любин, 1977). Учитывая то обстоятельство, что в среднем палеолите (мустье) Крыма использование долечных форм не характерно, вполне резонно видеть в комплексе каменных изделий Эчки 1 финальный ранний палеолит. С таким заключением согласуется и наличие изделий из менее качественного сырья (песчаника), также не характерного для мустье.

Внимательное ознакомление с литературой по раннему палеолиту Крыма позволило бесспорно идентифицировать местонахождение Эчки 1 как один из пунктов «памятников с галечными орудиями», открытый крымскими археологами А. А. Щепинским и А. А. Клюкиным в 1976 г. на Эчки-Даге (Щепинский, Клюкин, 1992. С. 104-108). К сожалению, среди наших находок бесспорных «галечных орудий» нет. Можно полагать, что это местонахождение следует рассматривать как часть более основательного поселения палеолитического времени, расположенного выше по склону и, возможно, связанного со скальным убежищем с сохранившимся культурным слоем. На местонахождении необходимо проведение более углубленного обследования, особенно стыка террасы и подножья хребта Эчки-Даг для поиска участка концентрации и сохранившихся мест непотревоженного залегания каменных изделий.

Местонахождение Коз. В июне 2014 г. А. Л. Чепалыгой при изучении террасовидной поверхности в глиняно-галечном карьере в центре села Солнечная Долина Судакского городского округа были собраны каменные предметы. Некоторые из них, по заключению Н. К. Анисюткина, можно рассматривать как изделия раннего палеолита (Чепальга и др., 2015. Рис. 4, 9, 10).

В 2016 г. С. А. Кулаковым и Н. К. Анисюткиным было тщательно осмотрено место сборов этих артефактов. Оно было приурочено к изолированному останцу террасовидной поверхности непосредственно в центре села, который в настоящее время используется как местный глиняно-галечный карьер площадью около 500 кв. м (рис. 3, 1). Эти террасовидные отложения были изучены А. Л. Чепалыгой. Они были определены и описаны как 100-метровая VIII Манджильская терраса позднего эоплейстоцена. Тринадцатиметровый разрез террасы состоит из переслаивающихся «песчано-гли- нисто-алевритовых» и галечных слоев, которые свидетельствуют о том, что эти отложения формировались в «прибрежные фации мелководного бассейна с активной волно-прибойной зоной» морской лагуны (Чепальга и др., 2015. С. 8-12).

Координаты разреза террасы, согласно данным А. Л. Чепалыги, «на левом берегу речки Коз в 1 км ниже ее выхода из гор и в 4 км от моря» составляют «N4452'21.08” E35²6'24.44”» (Там же. C. 7).

Работы 2016 г. ознаменовались обнаружением артефакта in situ в нижнем слое галечника разреза. Согласно стратиграфии А. Л. Чепалыги, артефакт залегал в слое 4, на глубине более 10 м от дневной поверхности (рис. 3, 2). Каменное изделие следует рассматривать как чоппер или массивное скребло с вогнутым лезвием, обработанным систематической крупнофасеточной ретушью на одной из длинных сторон плоской продолговатой гальки зеленовато-серой мелкозернистой породы. Орудие было заметно окатано.

Известно, что Х. Мовиус, первый выделивший чопперы, называл их большими и грубыми скреблами, отличающимися от обычных скребел лишь размерами (Movius, 1957. Р. 149-156). Позднее Ф. Борд предложил называть чоппером лишь орудие из галек или желваков кремня, оставив за формами из отщепов определение скребло (Bordes, 1961. Р. 47). В нашем случае данное орудие, которое изготовлено из обломка гальки, следует отнести именно к чопперам.

Эта находка послужила толчком для самого тщательного обследования осыпей стен и отвалов карьера. В результате работ была собрана представительная коллекция каменных изделий - 18 экз. Все предметы, крупных размеров, изготовлены из местного галечного сырья, в основном изверженных пород разной структуры и цветности. Основную часть коллекции составляют орудийные формы - чопперы и чопперовидные изделия (8 экз.), выполненные на гальках или их обломках. Остальные изделия - это разбитые гальки и галечные сколы, включая один нуклеус и два отщепа с ретушью. Все артефакты оглажены и окатаны в разной степени.

Для общего представления о коллекции приведем краткие описания характерных форм орудий. 

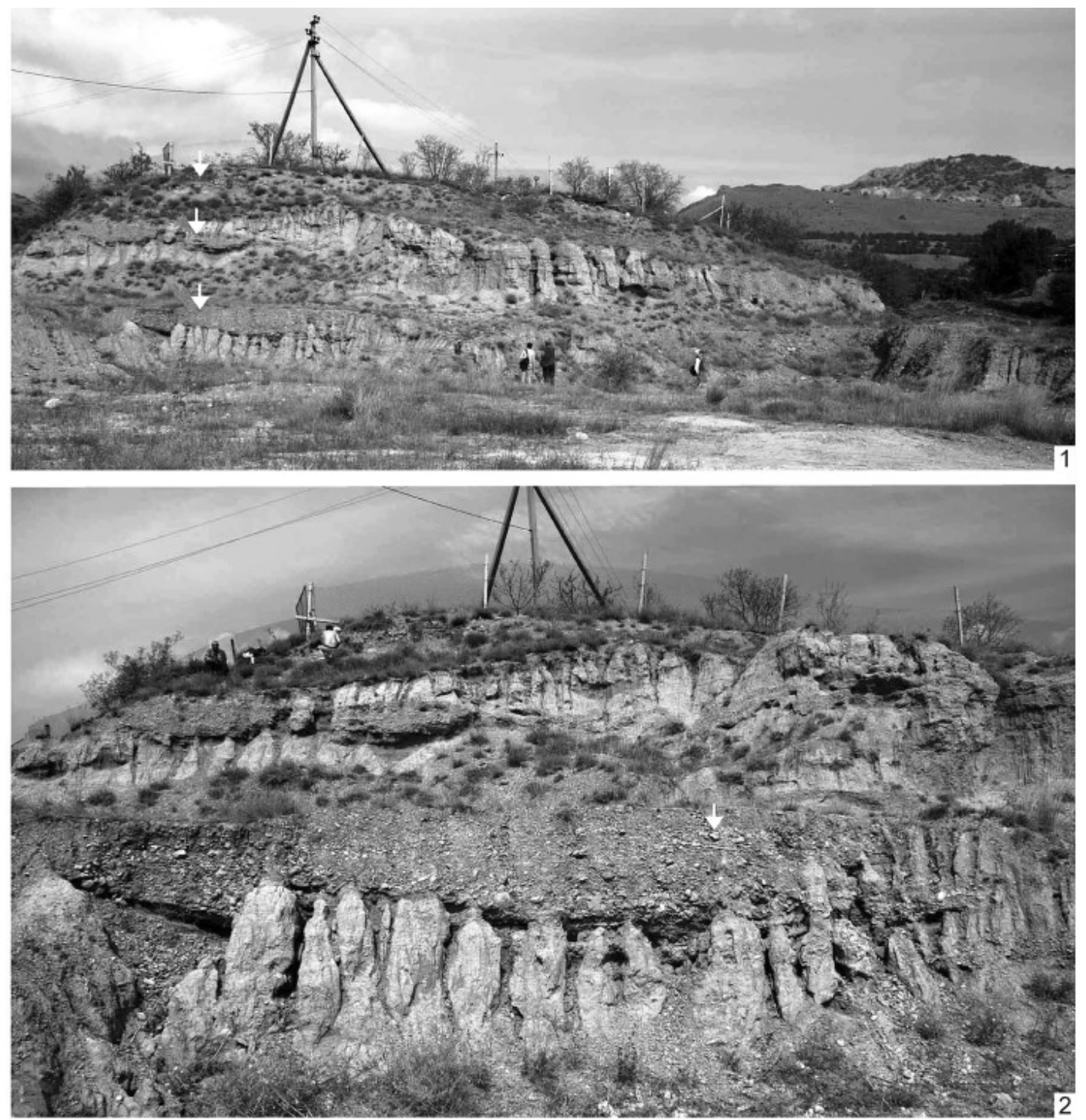

Рис. 3. Местонахождение Коз: 1 - карьер в центре села, вид с юго-запада (стрелками отмечены три горизонта галечника); 2 - артефакт in situ в нижнем уровне галечника (указано стрелкой), вид с юго-востока

Fig. 3. Site of Koz: 1 - quarry in the centre of the village, view from south-west (arrows mark the three horizons of sandstone); 2 - artefact in situ at the lower level of the pebble layer (marked with an arrow), view from south-east

Крупный концевой чоппер с одним распространенным и рельефным сколом, образующим выемчатый рабочий конец, изготовлен на гальке прочного кремнистого известняка. На противолежащем конце заметна забитость, которую можно интерпретировать как элемент аккомодации (рис. 4, 4). Подобные формы чопперов с одним распространенным сколом весьма характерны для древнейшего раннего палеолита (преашеля) Северной Африки (Ramendo, 1963. Р. 43-73). Французский ученый Анри де Люмлей назвал их первичными (choppers primaires) (Lumley et al., 2009a. P. 38).
Концевой чоппер с частичной двусторонней обработкой рабочего края изготовлен на удлиненной гальке небольших размеров. Противолежащий конец имеет следы забитости, которые указывают на возможное использование данного орудия также в качестве отбойника. Орудие можно описать как двусторонний чоппер или чоппинг (рис. 4,1 ).

Частично двустороннее орудие на окатанной гальке кремнистого песчаника следует отнести к боковым чоппингам с бифасиальной обработкой. Для последнего характерно извилистое лезвие, что отличает чоппинг от двустороннего чоппера, на что 


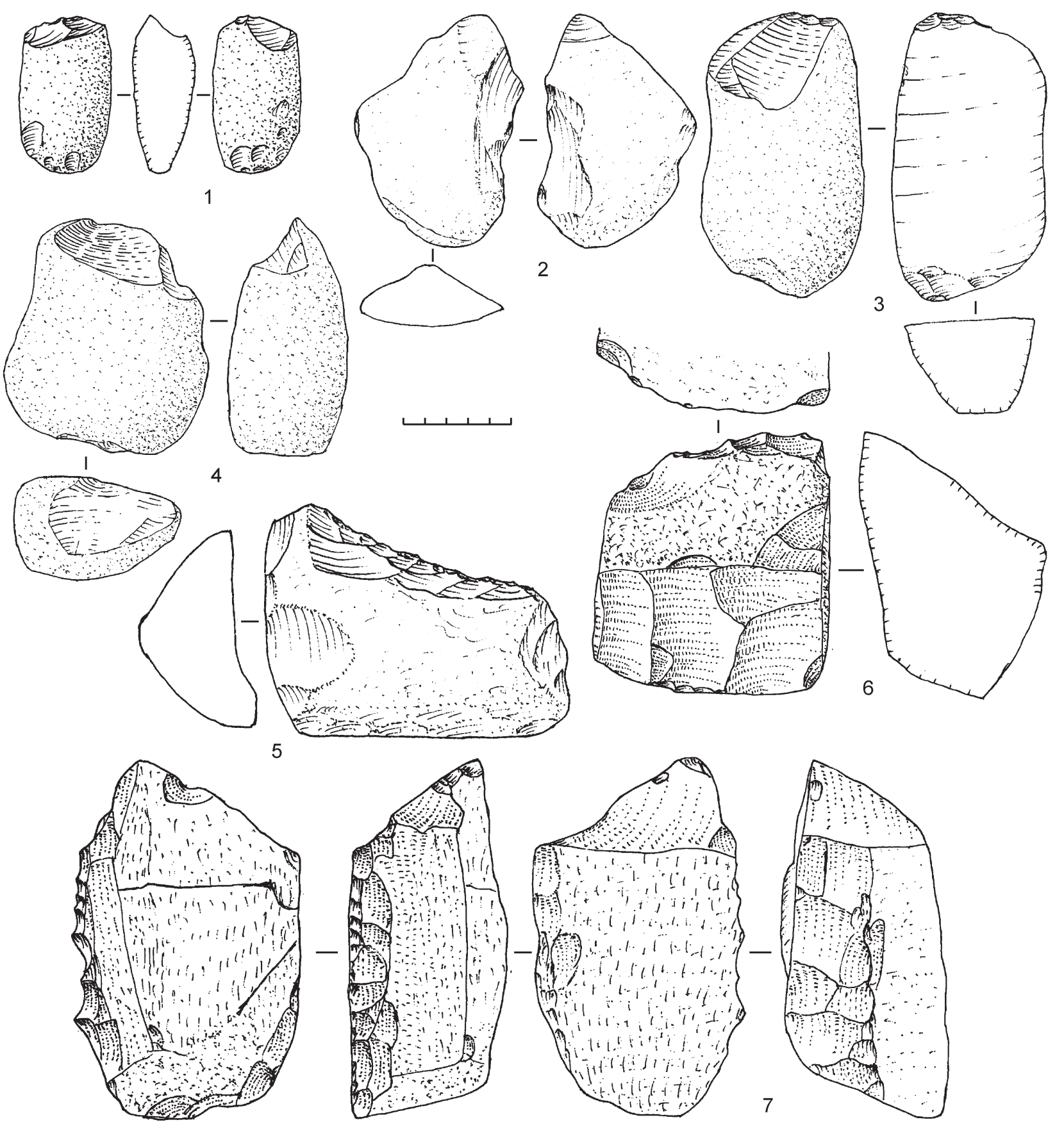

Рис. 4. Местонахождение Коз, артефакты: 1 - чоппинг; 2 - галечное орудие с двусторонней обработкой; 3 - удлиненный массивный скол с ретушью; 4, 5 - чопперы; 6 - чоппер на гальке с нуклевидными сколами; 7 - комбинированное орудие - пик и чоппер

Рисунки Н. К. Анисюткина

Fig. 4. Site of Koz, artefacts: 1 - chopping; 2 - pebble tool with bifacial treatment; 3 - elongated massive spall with retouch; 4, 5 - choppers; 6 - chopper on a pebble with core-shaped scars; 7 - combinated tool - pick and chopper

Drawings by N. K. Anisyutkin 
специально обращали особое внимание западные исследователи (Bordes, 1961. Р. 48). В нашем случае это орудие можно рассматривать также в качестве переходной формы к бифасам (рис. 4, 2).

Крупный и массивный в поперечном сечении первичный отщеп удлиненной формы с ударной площадкой, удаленной обработкой. На обоих концах имеется ретушь, в одном случае достаточно распространенная. Эту ретушь можно, в основном, воспринимать как следы утилизации. Один из обработанных концов сильно окатан (рис. 4,3 ).

Чоппер на окатанной гальке с выемчатым рабочим краем. Найден непосредственно в слое галечника (рис. 4,5 ).

Односторонний чоппер изготовлен на окатанном желваке крупных размеров. Выпуклый рабочий край выделен несколькими сколами, образующими зубчатое лезвие. На противолежащем крае есть четыре параллельно идущих нуклевидных снятия крупных размеров, имеющих, вероятно, аккомодационное значение (рис. 4, 6).

Крупное орудие на частично окатанном обломке изверженной породы имеет удлиненную подтреугольную форму с интенсивно обработанным однорядной и зубчатой ретушью продольным краем. На противолежащей стороне присутствует участок, оббитый встречной контрударной и отвесной ретушью, предназначенной для выделения обушка. Острый конец дополнительно выделен вентральным сколом, утончающим массивность острого конца. В данном случае орудие можно рассматривать в качестве специфического, где острие сочетается с протяженным зубчатым лезвием, что позволяет отнести его как к чопперам, так и пикам (рис. 4, 7).

Интерес представляет крупный многоплощадочный нуклеус, с которого при помощи ортогонального способа была снята серия широких отщепов. Подобные нуклеусы у нас назывались кубовидными (Замятнин, 1961).

Коллекция этого местонахождения имеет весьма архаичный облик и вполне может соответствовать древнейшему раннему палеолиту. Этому выводу соответствуют крупные галечные формы и характер их обработки. Возможно, преобладание крупных форм связано с особенностями сырья, из которого изготовлены каменные орудия. Как правило, в кол- лекциях памятников с хорошо или удовлетворительно сохранившимися слоями обычно многочисленны отщепы мелких размеров. В нашем случае такие отщепы, по причине их окатанности, плохо диагностируются, а поэтому случайны в коллекции. Можно указать на находку в 2015 г. единственного очень выразительного мелкого кремневого отщепа со слабой ретушью края. Как известно, в этом районе выходов кремня нет. Они находятся на расстоянии около 20-25 км от местонахождения. В этом случае очевидно, что кремень был принесен на стоянку древнейшими людьми.

Таким образом, разведывательные работы 2016 г. полностью подтвердили обнаружение в 20142015 гг. А. Л. Чепалыгой нового палеолитического местонахождения на южном берегу Крыма, которое получило название «Коз». Большая часть собранных здесь каменных изделий имеет явный раннепалеолитический облик. Обнаружение же С. А. Кулаковым чоппера непосредственно в галечнике эоплейстоценовой террасы, которая датируется возрастом до 1 млн лет назад (Чепальга, 2015. С. 28-42; Чепальга и др., 2015. С. 5-22), может служить доказательством глубокой древности местонахождения. Находки на местонахождении Коз архаичных каменных орудий, включая чопперы, в определенной мере являются подтверждением ранее высказанного предположения украинского археолога С. М. Жука о принадлежности найденных им в районе Ялты весьма примитивных каменных орудий к эоплейстоценовому или раннеплейстоценовому времени. Они, как и артефакты с местонахождения Коз, так же связаны с поверхностью высокой 100-метровой морской террасы (Жук, 1994. C. 102-111; Zuk, 1995. Р. 47-58).

Заключение. Археологические исследования подтвердили наличие артефактов раннего палеолита на высоких террасах Южного Крыма. Исследования местонахождения Эчки 1 показали, что артефакты с поверхности террасы не являются очень древними. По совокупности технико-морфологических показателей этот комплекс не древнее каменных индустрий развитого или даже позднего ашеля.

Напротив, находки из галечников 100-метровой террасы местонахождения Коз, которые являются поверхностями древних пляжей, имеют архаичный 
облик и вполне могут быть сопоставимы с самым ранним этапом нижнего палеолита. Не исключено, что основная их часть, обнаруженная на местонахождении Коз, может соответствовать комплексам типа Mode 1. Таким образом, стала очевидной необходимость проведения раскопок на местонахождении Коз для выявления находок непосредственно из древних отложений. ${ }^{4}$

При отсутствии пока необходимых данных, в частности палеомагнитных, укажем на проведенные в Южной Франции исследования, согласно которым все древние пляжные уровни побережья Средиземного моря высотой от 85 до 110 м соответствуют раннему плейстоцену или второй половине палеомагнитной эпохи Матуяма. В частности, уровень палеоберега высотой 85 м, выяв- ленного в районе Ниццы, залегал ниже инверсии 780000 лет. Грот же Валлоне с артефактами позднего олдована возрастом около 1 млн лет расположен на высоте 110 м (Lumley et al., 2009b. P.19-29). Эти данные косвенно могут быть использованы для доказательства аналогичного возраста артефактов из местонахождения Коз. Известно, что соотношение высоты и возраста террас является характерным для всей Средиземноморской области, включая Черное море (Марков, Величко, 1967. С. 387). Сейчас можно утверждать, что более 1 млн лет тому назад на территории Крыма появились первые предки ископаемого человека типа Homo erectus, проникшие из Африки в результате одной из волн расселения древнейшего человечества (Деревянко, 2015).

\footnotetext{
4 Раскопки, проведенные в 2017 г. на местонахождении Коз, полностью подтвердили наши выводы.
}

Жук, 1994 - Жук С. М. Археологические разведки и охранные раскопки в окрестностях Ялты. Археологические исследования в Крыму. 1993. Симферополь, 1994.

Замятнин, 1961 - Замятнин С. Н. Очерки по палеолиту. М.; Л., 1961.

Любин, 1977 - Любин В. П. Мустьерские культуры Кавказа. Л., 1977.

Марков, Величко, 1967 - Марков К. К., Величко А. А. Четвертичный период (ледниковый период - антропогенный период). М., 1967. Т. ІІІ: Материки и океаны.

Чепальга, 2015 - Чепальга А. Л. Новая концепция черноморских террас юго-восточного Крыма // БКИЧП. М., 2015. № 74.

Чепальга и др., 2015 - Чепальга А. Л., Анисюткин Н. К., Садчикова Т. А. Первые многослойные стоянки олдованской культуры в Крыму: геология, археология, палеоэкология // БКИЧП. М., 2015. № 74.

Щепинский, Клюкин, 1992 - Щепинский А. А., Клюкин А. А. Раннепалеолитическая «галечная культура» Крыма // КСИА. М., 1992. Вып. 206.

Bordes, 1961 - Bordes F. Typologie du Paleolithique ancient et moyen // Publications de L'Intitut de Prehistore de l'Universite de Bordeaux. Mem. I. Bordeaux, 1961.

Lumley et al., 2009a - Lumley H. de, Barsky D., Cauche D. Les premieres etapes de la colonisation de l'Europe et l'arrivee de l'Homme sur les rives de la Mediterranee // L'Anthropologie. Paris, 2009. Vol. 113.

Lumley et al., 2009b - Lumley H. de, Khatib S., Saos T. Evolution des rivages quaternaires sur le littoral mediterraneen de la region nicoise a la region Lanquedoc-Roussillon, dupuis 1500000 ans // Archeologie des rivages mtditerraneens: 50 ans de recherche. Actes du colloque d'Arles 28-29 octobre 2009. Editions errance 1'Ministere de la Culture et de la Communication.

Movius, 1957 - Movius H. L. Peblle-tool Terminology in India and Pakistan // Man in India. 1957. 37 (2).

Ramendo, 1963 - Ramendo L. Les galets amenages de Regan (Sahara). Lybica, 1963. T. 11.

Zuk, 1995 - Zuk S. About the Early Palaeolithic of the Crimea // Préhistoire Européene. Liège, 1955. No. 7. 


\title{
Studies of Early Palaeolithic sites on the high marine terraces of Southern Crimea in 2016
}

\author{
N. K. Anisyutkin, S. A. Kulakov, A. L. Tchepalyga
}

This paper presents the results of preliminary field investigations of 2016 in the locations of Koz and Echki. These sites are situated on high sea terraces of the Southern Coast of Crimea. The first finds of stone artefacts in the layers of pebbles on sea terraces of the Black Sea littoral were made in 2014-2015 by the palaeogeographer A. L. Tchepalyga. These artefacts were discovered during the selection of geological samples and were previously determined as Palaeolithic artefacts. Later they were attributed by N. K. Anisyutkin as artefacts of the Early and, possibly, Middle Palaeolithic. In 2016, the field research was supported by a grant of the Russian Foundation for Basic Research under the leadership of A. L. Tchepalyga. The archaeological research was directed by a well-known expert of the Palaeolithic of Caucasus S. A. Kulakov. N. K. Anisyutkin participated in these investigations as a scientific adviser.

The main studies were conducted at locations with relatively large amounts of the materials - Echki 1 and Koz. These locations are located close to each other on a 100-metre high sea terrace.

Echki 1. Several dozen of stone artefacts were found on the modern surface of the sea terrace. These artefacts are made mainly of andesite. There are also four tools in the collection, including two typical andesite side-scrapers. The technological and morphological analysis of the finds showed that the complex should be attributed to the Middle, or even Late, Acheulian.

Koz. The site of Koz is located in the centre of the village of Solnechnoye, in a pebble quarry in the valley of the Sudak city district. At this location, Palaeolithic objects of archaic type were discovered. According to our research, these artefacts come from ancient beaches of the Black Sea coast. The artefacts, including pebble forms, were made from rolled pebbles predominantly of a volcanic rock. Choppers and choppings predominate among the tools, there are also some cores and retouched flakes. One of the choppers was found immediately (in situ) in the gravel. This complex of stone tools is analogous to industries of Mode 1 type. It is widely accepted that all the high terraces (including the 100 metre high ones) belong to the Early Pleistocene, corresponding to the palaeomagnetic age of Matuyama. The conclusion of Tchepalyga that 100 metre high terraces are dated to the Early Pleistocene is confirmed by studies in France conducted on the Mediterranean coast in the Nice region (Lumley et al., 2009b. P. 19-29). According to these studies (Lumley et al., 2009b), all the ancient beaches above 85 metres high are aged more than 800 thousand years, corresponding to the Early Pleistocene. It is now firmly established that the ratio of height and age of the terraces is characteristic of the entire Mediterranean, including the Black Sea littoral.

At the locations of Koz and Echki, a group directed by A. L. Tchepalyga conducted interdisciplinary researches including palaeomagnetic studies. In 2017, at the site of Koz archaeological excavations were carried out, which confirmed all the conclusions of this article. The results of these studies will be published later. Artefacts, including a variety of choppers, were found immediately in pebbled sediments (in situ). 